\title{
Coculnol, a new penicillic acid produced by a coculture of Fusarium solani FKI-6853 and Talaromyces sp. FKA-65
}

\author{
Kenichi Nonaka ${ }^{1,2,3}$, Takuya Chiba ${ }^{2,3}$, Takuya Suga ${ }^{2}$, Yukihiro Asami ${ }^{1,2}$, Masato Iwatsuki ${ }^{1,2}$, \\ Rokuro Masuma ${ }^{1,2}$, Satoshi Ōmura ${ }^{1}$ and Kazuro Shiomi ${ }^{1,2}$
}

The Journal of Antibiotics (2015) 68, 530-532; doi:10.1038/ja.2015.15; published online 25 February 2015

Natural products hold significant potential for the development of new drugs and other chemical agents. The rate at which known compounds have been reisolated from natural sources has been increasing markedly during the past decade. ${ }^{1}$ Consequently, more efficient and diverse fermentation methods would be most beneficial in helping to avoid duplication of efforts. One such method is a coculture system that has the ability to not only produce novel natural products but also increase the productivity of compounds. ${ }^{2}$ Through our new coculture process we have already found several novel promising compounds. ${ }^{2}$ On further screening of 400 coculture broths using two fungal strains, we discovered that a coculture broth of Fusarium solani FKI-6853 and Talaromyces sp. FKA-65 produced a compound that showed notable anti-influenza virus activity against the strain A/PR/8/34 (H1N1). Bioassay-guided chromatographic fractionation of this coculture broth led to the isolation of a new penicillic acid derivative, coculnol (1; Figure 1). This paper describes the fermentation, isolation, structure elucidation and anti-influenza virus activity of 1 .

Fungal strains FKI-6853 and FKA-65 were isolated from the soil samples collected from Haha-jima, Bonin Islands, Tokyo, Japan and Kouzu island, Izu Islands, Tokyo, Japan, respectively. The internal transcribed spacer (ITS) sequences of the strains FKI-6853 and FKA-65 were decided and deposited at the DNA Data Bank of Japan with accession numbers LC002783 and LC002784, respectively. The ITS region of FKI-6853 and FKA-65 were compared with the

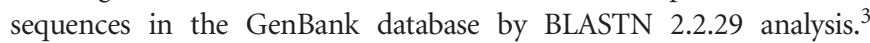
FKI-6853 showed a 99.5\% similarity with FMR 7141 (F. solani, GenBank accession number AM412637), and FKA-65 showed a 99.4\% similarity with CBS 133147 (ex-type of Talaromyces thailandensis, GenBank accession number JN898041). From the results of sequencing analyses, the producing strains FKI-6853 and FKA-65 were identified as F. solani and Talaromyces sp., respectively.

Strains FKI-6853 and FKA-65 were grown and maintained on a Miura's medium (LcA) slant consisting of $0.1 \%$ glycerol, $0.08 \%$
$\mathrm{KH}_{2} \mathrm{PO}_{4}, 0.02 \% \quad \mathrm{~K}_{2} \mathrm{HPO}_{4}, 0.02 \% \mathrm{MgSO}_{4} \cdot 7 \mathrm{H}_{2} \mathrm{O}, 0.02 \% \mathrm{KCl}, 0.2 \%$ $\mathrm{NaNO}_{3}, 0.02 \%$ yeast extract (Oriental Yeast Co., Ltd., Tokyo, Japan) and $1.5 \%$ agar (adjusted to $\mathrm{pH} 6.0$ before sterilization). A loop of spores of F. solani FKI-6853 was inoculated into $10 \mathrm{ml}$ of seed medium, consisting of $2.0 \%$ glucose, $0.2 \%$ yeast extract, $0.5 \%$ Polypepton (Nihon Pharmaceutical Co., Ltd., Tokyo, Japan), 0.05\% $\mathrm{MgSO}_{4} \cdot 7 \mathrm{H}_{2} \mathrm{O}, 0.1 \% \mathrm{KH}_{2} \mathrm{PO}_{4}$ and $0.1 \%$ agar (adjusted to $\mathrm{pH} 6.0$ before sterilization), in a test tube. The seed culture of Talaromyces sp. FKA-65 was also prepared in the same manner. The inoculated tubes were incubated on a reciprocal shaker $\left(300\right.$ r.p.m.) at $27^{\circ} \mathrm{C}$ for 3 days.

For the production of 1 , each $1-\mathrm{ml}$ portion of the seed cultures of FKI-6853 and FKA-65 was transferred to each of thirty 500-ml Erlenmeyer flasks containing $100 \mathrm{ml}$ of the production medium, consisting of 3.0\% purple sweet potato powder (Mikasa Sangyo Co., Ltd., Yamaguchi, Japan), 2.0\% soluble starch, 1.0\% soft brown sugar (Mitsui Sugar Co., Ltd., Tokyo, Japan), 1.0\% wheat bran (Nisshin Pharma Inc., Tokyo, Japan), 0.5\% Polypepton (Nihon Pharmaceutical Co., Ltd.), $0.2 \%$ dry yeast, $0.1 \%$ aloe powder (Tonooka Shoten Co., Ltd., Shizuoka, Japan), $0.1 \%$ tomorrow leaf powder (Tonooka Shoten Co., Ltd.), $0.05 \% \mathrm{KH}_{2} \mathrm{PO}_{4}$ and $0.05 \% \mathrm{MgSO}_{4} \cdot 7 \mathrm{H}_{2} \mathrm{O}$ (adjusted to $\mathrm{pH}$ 6.0 before sterilization). Fermentation was carried out on a rotary shaker (210 r.p.m.) at $27^{\circ} \mathrm{C}$ for 6 days.

The whole-culture broth $(3000 \mathrm{ml})$ was subsequently added to an equal amount of ethanol and then filtered. The filtrate was concentrated under reduced pressure to remove $\mathrm{EtOH}$ and then passed through an octadecylsilyl (ODS) open column (Pegasil Prep ODS-7515-12A, 2012A, 20 (Senshu Scientific Co., Tokyo, Japan)). The pass fraction was applied to a SP-207 open column (Mitsubishi Chemical Corporation, Tokyo, Japan) using the $\mathrm{H}_{2} \mathrm{O} / \mathrm{MeOH}$ solvent system. The column was eluted with $\mathrm{MeOH}(500 \mathrm{ml})$ after washing with 0,20 , 40 and $60 \% \mathrm{MeOH}$ aq (each $500 \mathrm{ml}$ ). The concentrated $\mathrm{MeOH}$ eluent $(121 \mathrm{mg})$ was dissolved in $\mathrm{MeOH}(12 \mathrm{ml})$ and purified by preparative HPLC (Develosil C30-UG, 20ф×250 mm, Nomura Chemical, Aichi, Japan) with $23 \% \mathrm{MeOH} / 0.1 \%$ trifluoroacetic acid at a flow rate of

${ }^{1}$ Kitasato Institute for Life Sciences, Kitasato University, Tokyo, Japan and ${ }^{2}$ Graduate School of Infection Control Sciences, Kitasato University, Tokyo, Japan ${ }^{3}$ These authors contributed equally to this work.

Correspondence: Professor S Ōmura or Professor K Shiomi, Kitasato Institute for Life Sciences, Kitasato University, 5-9-1 Shirokane, Minato-ku, Tokyo 108-8641, Japan. E-mail: omuras@insti.kitasato-u.ac.jp or shiomi@lisci.kitasato-u.ac.jp

Received 4 October 2014; revised 13 December 2014; accepted 19 December 2014; published online 25 February 2015 
$8 \mathrm{ml} \mathrm{min}{ }^{-1}$ detected at UV $250 \mathrm{~nm}$. A peak of the retention time of 1 43-46 min was collected and concentrated in vacuo to afford 1 (8.1 mg).

Compound 1 was obtained as a white syrup, UV $(\mathrm{MeOH}) \lambda_{\max }$ $(\log \varepsilon): 268(0.692) \mathrm{nm}$. The molecular formula of 1 was elucidated as $\mathrm{C}_{8} \mathrm{H}_{10} \mathrm{O}_{4}$ with four degrees of unsaturation by high-resolution electron impact mass spectrometry $\left(\mathrm{m} / z 170.0582\left[\mathrm{M}^{+}\right]\right.$(calcd for $\mathrm{C}_{8} \mathrm{H}_{10} \mathrm{O}_{4}$, 170.0579). The IR spectrum $(\mathrm{KBr})$ of 1 showed characteristic absorptions at 3413,1751 and $1604 \mathrm{~cm}^{-1}$, suggesting the presence of hydroxyl and carbonyl groups. The ${ }^{1} \mathrm{H}$ and ${ }^{13} \mathrm{C}$ NMR spectra of 1 in $\mathrm{CD}_{3} \mathrm{OD}$ are summarized in Table 1 . The ${ }^{1} \mathrm{H}$ and ${ }^{13} \mathrm{C}$ NMR and HSQC indicated the presence of one methoxy $\left(\delta_{\mathrm{H}} 3.97, \delta_{\mathrm{C}} 60.3\right)$, one olefinic methyl $\left(\delta_{\mathrm{H}} 2.01, \delta_{\mathrm{C}} 15.2\right)$, one oxymethylene $\left(\delta_{\mathrm{H}} 4.45, \delta_{\mathrm{C}}\right.$ $59.9)$, one $s p^{2}$ methine $\left(\delta_{\mathrm{H}} 5.49, \delta_{\mathrm{C}} 91.4\right)$, four $s p^{2}$ quaternary carbons $\left(\delta_{\mathrm{C}} 126.5,141.2,170.5\right.$ and 172.6). The structure of 1 was elucidated<smiles>COC1=CC(=O)O/C1=C(/C)CO</smiles>

Coculnol (1)<smiles>C=C(C)C1(O)OC(=O)C=C1OC</smiles>

Penicillic acid (2)
Figure 1 Structures of coculnol (1) and penicillic acid (2).

Table $1{ }^{1} \mathrm{H}$ and ${ }^{13} \mathrm{C}$ NMR data for coculnol (1; recorded at $400 / 100 \mathrm{MHz}$ in $\mathrm{CD}_{3} \mathrm{OD} ; \delta$ in p.p.m.) and penicillic acid (2)

\begin{tabular}{lrrrrc}
\hline & \multicolumn{2}{c}{ Coculnol (1) } & & \multicolumn{2}{c}{ Penicillic acid (2) ${ }^{\mathrm{b}}$} \\
\cline { 2 - 3 } \cline { 5 - 6 } Position & ${ }^{13} \mathrm{C}$ & ${ }^{1} \mathrm{H}(\mathrm{J}$ in $\mathrm{Hz})$ & & ${ }^{13} \mathrm{C}$ & ${ }^{1} \mathrm{H}(\mathrm{J}$ in Hz$)$ \\
\hline 1 & 170.5 & - & 181.2 & - \\
2 & 91.4 & $5.49(1 \mathrm{H}, \mathrm{s})$ & 89.4 & $5.48(1 \mathrm{H}, \mathrm{s})$ \\
3 & 172.6 & - & 170.8 & - \\
4 & 141.2 & - & 101.8 & - \\
5 & 126.5 & - & 139.8 & - \\
6 & 59.9 & $4.45(2 \mathrm{H}, \mathrm{s})$ & 116.5 & $5.12(1 \mathrm{H}, \mathrm{s})$ \\
& & & & $5.22(1 \mathrm{H}, \mathrm{s})$ \\
7 & 60.3 & $3.97(3 \mathrm{H}, \mathrm{s})$ & 59.7 & $3.91(3 \mathrm{H}, \mathrm{s})$ \\
\hline & 15.2 & $2.01(3 \mathrm{H}, \mathrm{s})$ & 17.3 & $1.77(3 \mathrm{H}, \mathrm{s})$ \\
\hline
\end{tabular}

ameasured in $\mathrm{CD}_{3} \mathrm{OD}$.

bMeasured in $\mathrm{CDCl}_{3}{ }^{\text {i }}$
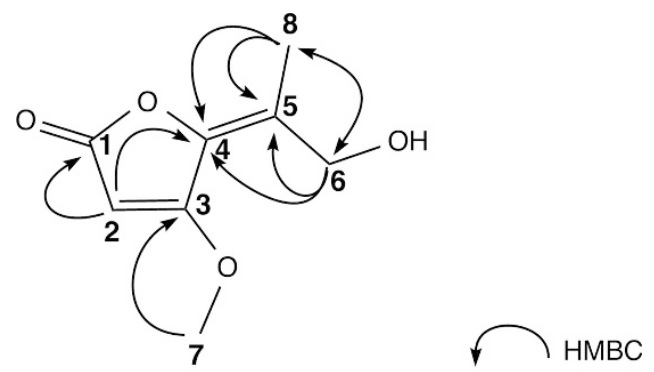

Coculnol (1)

Figure 2 HMBC correlations of coculnol (1). by the HMBC spectrum (Figure 2). The HMBC correlations of $\mathrm{H}-2$ / $\mathrm{C}-1$ and $\mathrm{C}-4$, and $\mathrm{H}_{3}-7 / \mathrm{C}-3$ suggested $\beta$-methoxy- $\alpha, \beta$-unsaturated $\gamma$ lactone ring substituted with an exo-olefinic moiety at $\mathrm{C}-4$. In addition, $\mathrm{HMBC}$ correlations observed at $\mathrm{H}_{3}-8 / \mathrm{C}-4, \mathrm{C}-5$ and $\mathrm{C}-6$ and $\mathrm{H}_{2}-6 / \mathrm{C}-4, \mathrm{C}-5$ and $\mathrm{C}-8$ allowed us to elucidate the structure of $\mathbf{1}$ as shown in Figure 1. Compound $\mathbf{1}$ was very similar to a known compound, penicillic acid (2). ${ }^{5}$ The comparison of chemical shifts in ${ }^{13} \mathrm{C}$ NMR between 1 and $2^{6,7}$ also supported this planar structure. We tried to determine the geometry of the tetra-substituted double bond between C-4 and C-5 of 1, but we could not observe any NOE correlations to confirm it. It was also impossible to determine this
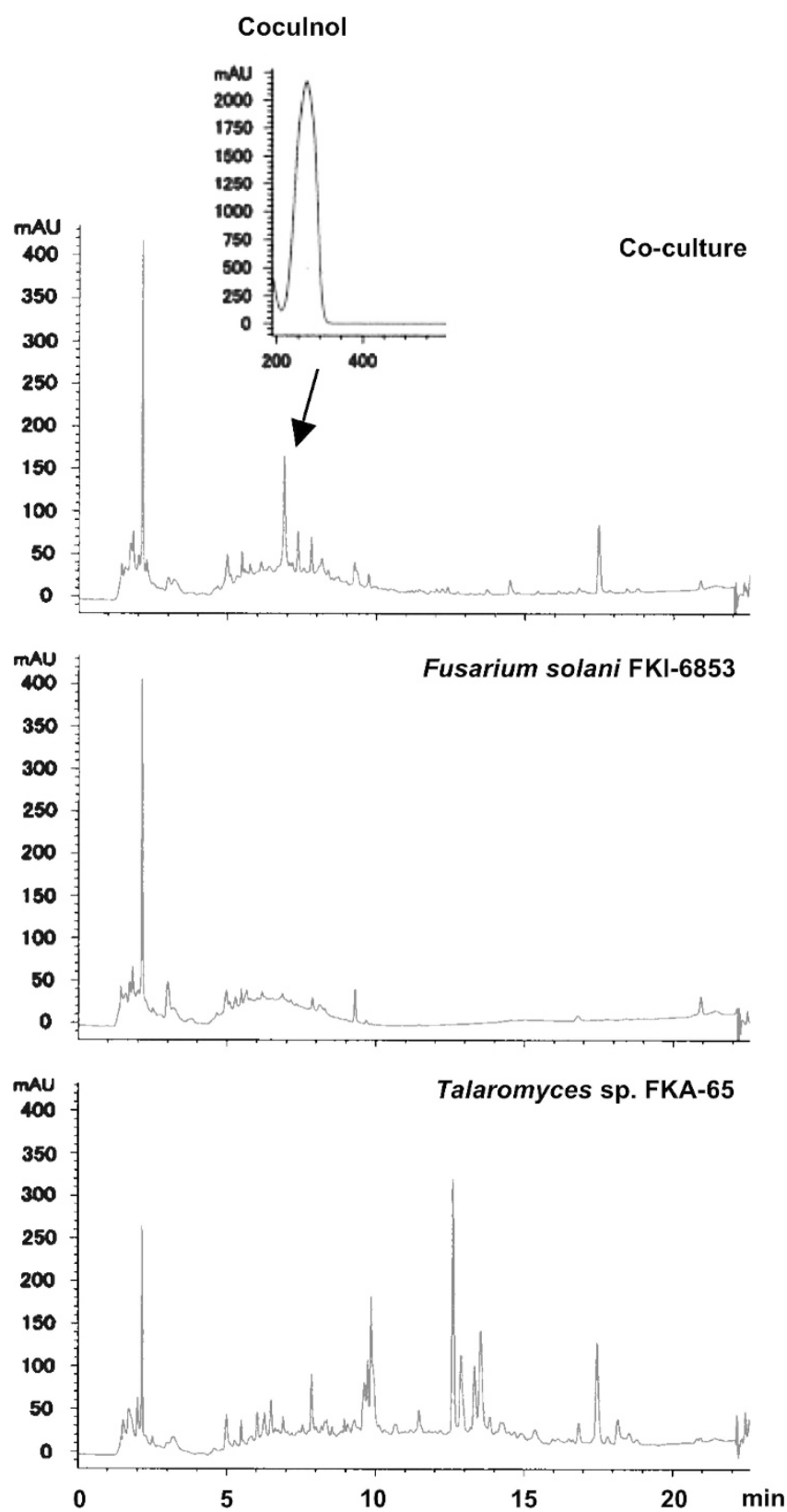

Figure 3 HPLC chromatograms of coculture and pure culture extract. UV spectrum is the data for coculnol (1) produced by coculture. HPLC conditions: column, symmetry $\mathrm{C} 18(2.1 \phi \times 150 \mathrm{~mm}$, Waters, Milford, MA, USA); UV detection, $210 \mathrm{~nm}$; flow rate, $0.2 \mathrm{ml} \mathrm{min}^{-1}$; mobile phase, $\mathrm{CH}_{3} \mathrm{CN}$ aq with $0.05 \%$ phosphoric acid, $5-100 \%$ (20 min). 
geometry by the comparison of chemical shifts with compounds of similar structure. Finally, this geometry was suggested to be $E$ by very small long-range coupling between $\mathrm{H}-2$ and $\mathrm{H}_{3}-8$ in decoupling experiments. ${ }^{8}$

In vitro anti-influenza A virus activity of $\mathbf{1}$ was evaluated by the multicycle replication method with Madin-Darby canine kidney (MDCK) cells, as previously described. ${ }^{9-11}$ Compound $\mathbf{1}$ showed an inhibitory effect (with $\mathrm{IC}_{50}$ value of $283 \mu \mathrm{g} \mathrm{ml}^{-1}$ ) against A/PR/8/34 (H1N1) with weak cytotoxicity against MDCK cells ( $\mathrm{IC}_{50}$ value of $781 \mu \mathrm{g} \mathrm{ml}^{-1}$ ). Further studies are required to establish the mode of action of 1 .

The coculture broth of F. solani FKI-6853 and Talaromyces sp. FKA-65 was active against influenza virus, but pure culture broths of either strain alone exhibited no activity. The isolated active compound was named coculnol. In addition, from the results of HPLC analysis, 1 was produced only by coculturing these two fungal strains (Figure 3 ). The results of our studies demonstrate the value of the coculture system for the discovery of new compounds.

\section{ACKNOWLEDGEMENTS}

We are grateful to Dr Kenichiro Nagai and Ms Noriko Sato, School of Pharmacy, Kitasato University for measurements of MS and NMR spectra. This work was supported, in part, by funding from the Quality Assurance Framework of Higher Education from the Ministry of Education, Culture,
Sports, Science and Technology, Japan (MEXT) and a Kitasato University Research Grant for Young Researchers.

1 Chin, Y. W., Balunas, M. J., Chai, H. B. \& Kinghorn, A. D. Drug discovery from natural sources. AAPS J. 8, E239-E253 (2006).

2 Nonaka, K. et al. Enhancement of metabolites productivity of Penicillium pinophilum FKI-5653, by co-culture with Trichoderma harzianum FKI-5655. J. Antibiot. (Tokyo) 64, 769-774 (2011)

3 Altschul, S. F. et al. Gapped BLAST and PSI-BLAST: a new generation of protein database search programs. Nucleic Acids Res. 25, 3389-3402 (1997)

4 Manoch, L., Dethoup, T., Yilmaz, N., Houbraken, J. \& Samson, R. A. Two new Talaromyces species from soil in Thailand. Mycoscience 54, 335-342 (2013).

5 Birkinshaw, J. H. et al. Studies in the biochemistry of micro-organisms: penicillic acid a metabolic product of Penicillium puberulum Bainier and P. cylopium Westling. Biochem. J. 30, 394-411 (1936).

6 Pohland, A. E., Schuller, P. L. \& Steyn, P. S. Physicochemical data for some selected mycotoxins. Pure Appl. Chem. 54, 2219-2284 (1982).

7 Kimura, Y., Nakahara, S. \& Fujioka, S. Aspyrone, a nematicidal compound isolated from the fungus, Aspergillus melleus. Biosci. Biotech. Biochem. 60 1375-1376 (1996).

8 Sardella, D. J. \& Vogal, G. Absolute signs of four-, five-, and six-bond proton-proton coupling constants in two anhydrides. J. Phys. Chem. 74, 4532-4537 (1970).

9 Nagai, T., Miyaichi, Y., Tomimori, T., Suzuki, Y. \& Yamada, H. In vivo anti-influenza virus activity of plant flavonoids possessing inhibitory activity for influenza virus sialidase. Antiviral Res. 19, 207-217 (1992).

10 Ōmura, S. et al. Wickerol and process for production thereof. W02009/116604 (2009).

11 Yamamoto, T. et al. Wickerols A and B: novel anti-influenza virus diterpenes produced by Trichoderma atroviride FKI-3849. Tetrahedron 68, 9267-9271 (2012). 